\title{
Congenital Cervical Teratoma Mimicking as Neuroblastoma on Cytology: A Diagnostic Pitfall
}

\begin{abstract}
Cervical teratomas are very rare tumors, accounting for approximately $3 \%-5 \%$ of all pediatric teratomas with predominance in females. Most common site of cervical teratoma is sacrococcygeal region and occurrence in cervical region is a rare presentation. We present a case of cervical teratoma in a 4-month-old male infant presenting as neck mass mimicking as neuroblastoma with differentiation on fine-needle aspiration. The final diagnosis of mature teratoma was made on histopathological examination.
\end{abstract}

Keywords: Congenital, fine-needle aspiration cytology, neuroblastoma, teratoma

\section{Introduction}

The word teratoma is derived from a Greek word meaning monster. Classically, it is composed of tissues from all the three germ cell layers, i.e., ectoderm, mesoderm, and endoderm. ${ }^{[1]}$ Most common location of teratoma is sacrococcygeal region, and cervical region is a less common site. ${ }^{[2]}$ Although usually histologically benign cervical teratomas because of their location and size can cause airway obstruction. ${ }^{[3]}$ The present case report emphasizes on the rarity of cervical teratoma and difficulties faced on fine-needle aspiration cytology (FNAC) of these tumors with histopathology as a gold standard for definitive diagnosis of this entity.

\section{Case Report}

A 4-month-old male infant presented to the surgical outpatient department with chief complaints of left-sided neck mass present since birth. The swelling measured approximately $3.5 \mathrm{~cm} \times 2.5 \mathrm{~cm}$ and was progressively increasing in size. The child was feeding well with normal sensory and motor milestones. There were no symptoms of respiratory distress. Ultrasonographic findings revealed a mass measuring $3.7 \mathrm{~cm} \times 2.5 \mathrm{~cm}$ having solid and cystic component with increased vascularity in the left submandibular region. Further, the child

This is an open access journal, and articles are distributed under the terms of the Creative Commons Attribution-NonCommercial-ShareAlike 4.0 License, which allows others to remix, tweak, and build upon the work non-commercially, as long as appropriate credit is given and the new creations are licensed under the identical terms.

For reprints contact: WKHLRPMedknow_reprints@wolterskluwer.com underwent a computed tomographic scan which revealed a complex heterogenous solid cystic enhancing mass lesion in the left cervical region with extensions into the left parapharyngeal space and inferiorly till the medial end of the clavicle [Figure 1]. Possibility of cervical teratoma was kept, and FNAC was advised.

\section{Cytological findings}

Aspiration was done from both solid and cystic areas. On FNAC from solid area, the smears were cellular comprising predominantly of medium-to-large sized cells having abundant eosinophilic granular cytoplasm with few spindle-shaped cells. Abundant granular fibrillary material was noted in the background [Figure 2]. At few places, acinar/pseudorosette pattern was also observed. No mitotic activity was noted. FNAC from cystic area yielded $2 \mathrm{ml}$ hemorrhagic fluid. No cellular elements were seen. A diagnosis of the neurogenic tumor was suggested on the basis of findings observed, and biopsy was advised. Subsequently, the child underwent excision biopsy, and the specimen was sent for histopathological examination.

\section{Histopathological findings}

Grossly, the tumor was gray-white to hemorrhagic, globular and encapsulated measuring $5 \mathrm{~cm} \times 4 \mathrm{~cm} \times 2 \mathrm{~cm}$. Cut section had a variegated appearance with focal areas of cystic degeneration [Figure 3]. Microscopic examination revealed a

How to cite this article: Chhabra S, Dhingra H,
Baliyan A, Singh A, Suri V. Congenital cervical
teratoma mimicking as neuroblastoma on cytology:
A diagnostic pitfall. Indian J Med Paediatr Oncol
2020;41:86-8.

\section{Sahil Chhabra ${ }^{1}$, Harshi Dhingra ${ }^{1}$, Asif Baliyan', Amarjit Singh ${ }^{1}$, Vijay Suri ${ }^{1}$}

${ }^{1}$ Department of Pathology, Adesh Institute of Medical Sciences and Research, Bathinda, Punjab, India, ${ }^{2}$ Focus Imaging and Research Centre Private Ltd, New Delhi, India

Submitted: $25-$ Mar-2018 Accepted in Revised Form: 21-Jun-2018

Published: 24-Apr-2020

Address for correspondence:

Dr. Harshi Dhingra,

Department of Pathology,

Adesh Institute of Medical

Sciences and Research,

Bathinda - 151 001,

Punjab, India.

E-mail: drharshidhingra@gmail. com

Access this article online

Website: www.ijmpo.org

DOI: 10.4103/ijmpo.ijmpo_68_18

Quick Response Code:

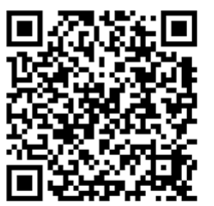




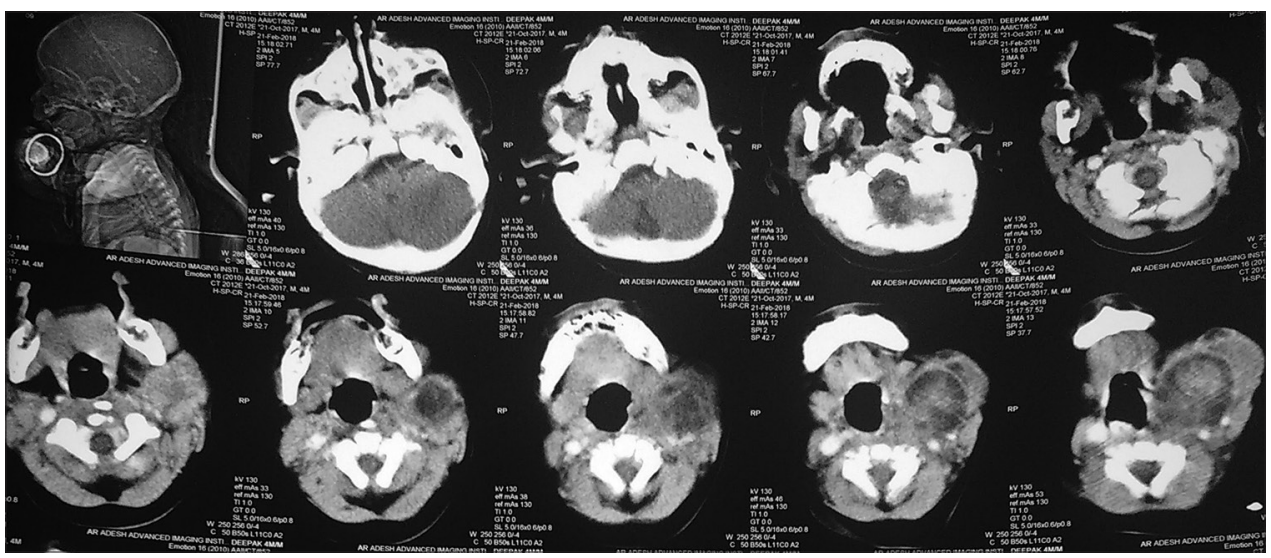

Figure 1: Contiguous axial scans of neck swelling showing complex heterogeneous solid-cystic mass

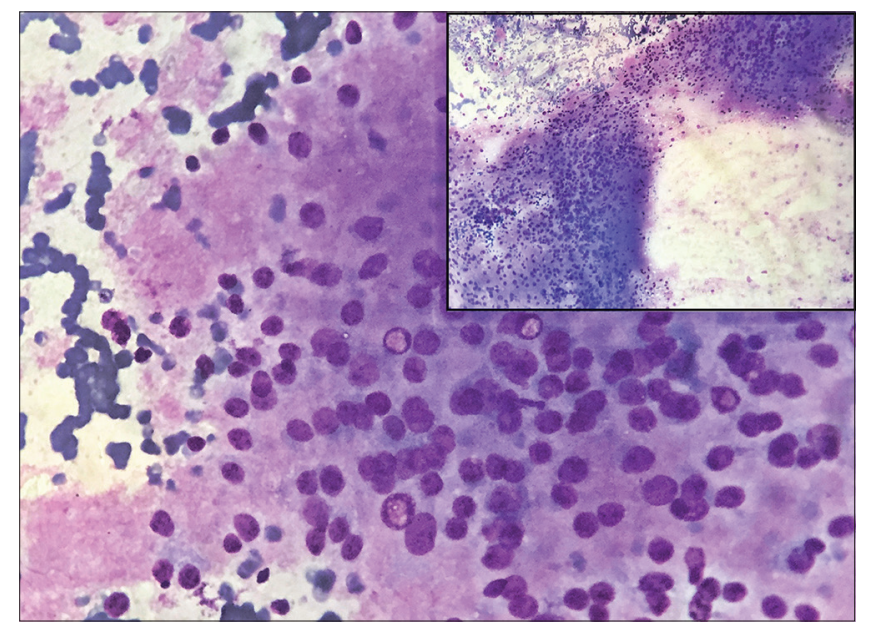

Figure 2: Fine-needle aspiration smears show round medium-to-large cells embedded in granular fibrillary material which led to erroneous diagnosis of neuroblastoma. On histopathology, these were found to be nuclei of oligodendrocytes and astrocytes (May-Grünwald Giemsa, ×400) Inset (May-Grünwald Giemsa, ×100)

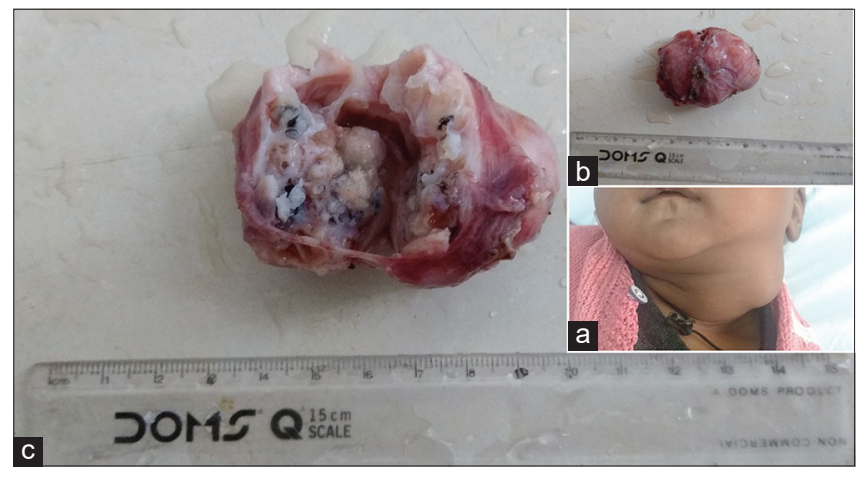

Figure 3: (a) Infant with left lateral neck mass. (b) Encapsulated lobulated mass on gross examination. (c) Cut section of the tumor is variegated with solid and cystic areas

tumor showing predominantly mature neuroepithelial tissue along with derivatives from all the three germ cell layers. Ectodermal components comprised stratified squamous epithelium, neural tissue having astrocytes, oligodendrocytes, and the choroid plexus tissue. The mesodermal components included muscle along with sebaceous glands, cartilage, adipose, and fibroconnective tissue. The endodermal components were respiratory and intestinal epithelium with thyroid follicular epithelium. A microscopic focus of immature neuroepithelial component was also seen. Thus, the final diagnosis of mature teratoma was made [Figures 4 and 5].

\section{Discussion}

Teratomas illustrate the relationship of histological maturity to the biological behavior. They may occur as mature teratomas consisting of well-differentiated tissues containing all the three germ cell layer derivatives. ${ }^{[1]}$ Immature teratomas have predominant primitive neuroepithelial component. All immature teratomas having malignant foci or metastasis are considered malignant. ${ }^{[3]}$ Teratomas can also occur as a part of malignant-mixed germ cell tumors wherein the malignant component is usually of germ cell origin that may be yolk sac tumor, seminoma, embryonal carcinoma, or choriocarcinoma and only rarely of somatic origin. ${ }^{[1]}$ In our case, a small component of immature neuroepithelium was noted. However, there was no evidence of any other germ cell component in the form of embryonal or yolk sac tumor. By definition, all the components present in mature cystic teratomas should appear histologically mature. However, on occasions, one sees microscopic focus of immature tissue in them. The behavior of these tumors, which should be distinguished from immature teratomas, is usually benign. ${ }^{[4]}$

Teratomas are most commonly located in the sacrococcygeal region followed by ovaries, testes, anterior mediastinum, retroperitoneum, and finally, the head-and-the neck region ${ }^{[2]}$ indicating the rarity of site of teratoma in our study.

Cervical teratomas are uncommon in neonates accounting for approximately $3 \%-5 \%$ of all pediatric teratomas occurring approximately in $1 / 40,000$ births. $^{[1]}$ Literature states female preponderance with male: female ratio being 1:3. ${ }^{[5]}$ However, our case reports the incidence in a 4-month-old male child.

Various clinical differential diagnosis in neck swellings in infants include lymphangiomas or cystic hygromas, 


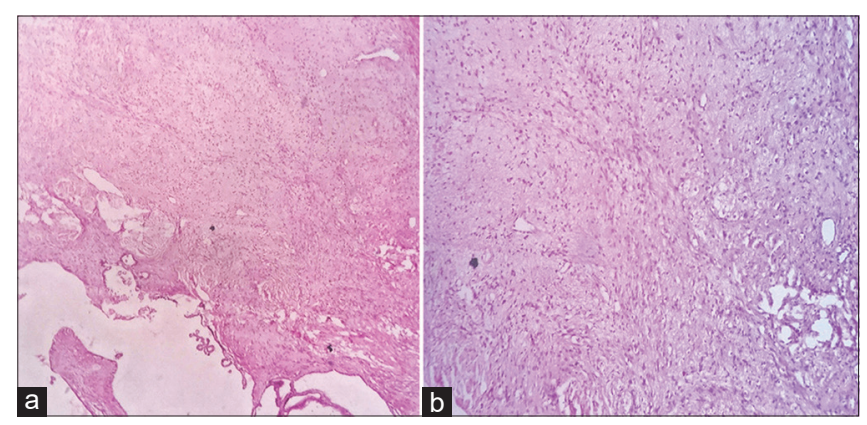

Figure 4: Histopathology photomicrograph shows abundant neuroepithelial component comprising oligodendrocytes and few astrocytes (a) (H and E, $\times 40)$, (b) (H and E, $\times 100)$

hemangiomas, branchial cysts, cervical neuroblastoma, soft-tissue sarcomas, congenital cervical goiter, and cervical teratoma. ${ }^{[6]}$

Cytology has limitation in the diagnosis of teratomas unless various cell types are observed. In our case also, FNAC diagnosis of neuroblastoma with differentiation was suggested. Similar diagnostic pitfall was faced by Sharmal and Mishra while aspirating an immature teratoma and diagnosis was given as neuroblastoma. It was suggested that aspiration from multiple sites is necessary to overcome these problems. ${ }^{[7]}$ Chao et al. also experienced similar problems in the diagnosis of immature teratomas and mixed germ cell tumors by cytology. ${ }^{[8]}$ On viewing FNAC slides retrospectively, we noticed that our needle went into an area of mature glial-tissue consisting predominantly of oligodendrocytes. Hence, this led to the diagnosis of neurogenic tumor.

The prognosis of mature teratoma is far better than other childhood tumors such as neuroblastoma and Wilms tumor. Majority of teratomas in infancy and childhood are benign as observed in study done by Sharmal and Mishra. ${ }^{[7]}$ This is in concordance to our case.

Management of cervical teratoma focuses on early resection of the tumoral mass to prevent complications such as respiratory distress due to the size. Immature, unresectable and recurring teratomas are, however, treated with adjuvant chemotherapy. ${ }^{[9]}$ Since the tumor in our case report was mature teratoma having small size; hence, it was completely resected. Postsurgical follow-up was uneventful.

To conclude, congenital cervical teratomas are rare germ cell tumors. Complete clinical, radiological and pathological examination should be carried out to reach the diagnosis. Although FNAC is helpful in reaching the diagnosis, it can pose problems in selective sampling of an area and histopathological diagnosis remains the gold standard for final diagnosis of this entity.

\section{Declaration of patient consent}

The authors certify that they have obtained all appropriate patient consent forms. In the form the patient(s) has/have

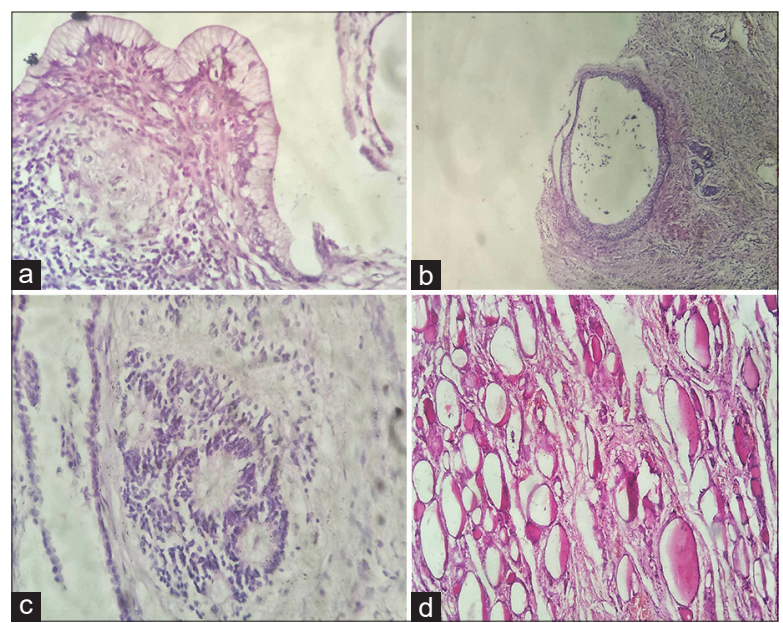

Figure 5: Photomicrograph of tumor depicts germ cell layers derivatives including (a) mucinous epithelium, (b) squamous epithelium, (c) a focus of immature neuroepithelium, and (d) thyroid follicular epithelium

given his/her/their consent for his/her/their images and other clinical information to be reported in the journal. The patients understand that their names and initials will not be published and due efforts will be made to conceal their identity, but anonymity cannot be guaranteed.

Financial support and sponsorship

Nil.

\section{Conflicts of interest}

There are no conflicts of interest.

\section{References}

1. Sellami M, Mnejja M, Ayadi L, Charfeddine I, Boudawara T, Hammami B, et al. Congenital teratoma of the neck: A case report and literature review. Egypt J Ear Nose Throat Allied Sci 2015;16:101-4.

2. Bergé SJ, von Lindern JJ, Appel T, Braumann B, Niederhagen B. Diagnosis and management of cervical teratomas. $\mathrm{Br} \mathrm{J}$ Oral Maxillofac Surg 2004;42:41-5.

3. Alharbi ST, Alsaadi AS, Yosuph AU, Abdulhameed FD, Arkoubi MM. Diagnostic imaging and surgrical management of a congenital cervical teratoma. J Taibah Univ Med Sci 2018;13:83-6.

4. Yanai-Inbar I, Scully RE. Relation of ovarian dermoid cysts and immature teratomas: An analysis of 350 cases of immature teratoma and 10 cases of dermoid cyst with microscopic foci of immature tissue. Int J Gynecol Pathol 1987;6:203-12.

5. Uchiyama M, Iwafuchi $M$, Naitoh $S$, Matsuda $Y$, Naitoh $M$, Yagi M, et al. A huge immature cervical teratoma in a newborn: Report of a case. Surg Today 1995;25:737-40.

6. Rauff S, Kien TE. Ultrasound diagnosis of fetal neck masses: A case series. Case Rep Obstet Gynecol 2013;2013:243590.

7. Sharmal S, Mishra K. Limitations in the diagnosis of childhood teratoid lesions on fine needle aspiration cytology. Acta Cytol 2010;54:142-7.

8. Chao TY, Nieh S, Huang SH, Lee WH. Cytology of fine needle aspirates of primary extragonadal germ cell tumors. Acta Cytol 1997;41:497-503.

9. Azizkhan RG, Caty MG. Teratomas in childhood. Curr Opin Pediatr 1996;8:287-92. 